\title{
Information needs for building a foundation for enhancing sustainable tourism as a development goal: an introduction
}

\author{
Stephen F. McCool
}

\section{Introduction}

Societies flourish when their members connect with and bond to their heritage, both cultural and natural. Understanding and appreciating that heritage is part of the human condition, so much so that otherwise we are lost as a species. This heritage and the connections it provides may be recreational (as when we seek outcomes such as adventure, challenge, escape, solitude and stress release), educational (such as learning about natural processes), cultural (such as appreciating how our societies have developed and understanding notable events of the past), spiritual, or utilitarian (such as harvesting resources for sustenance and shelter). The heritage values that support these connections, whether a remote landscape of the arctic, an historically significant cultural event in Asia, or a small protected forest in Eastern Europe, require careful stewardship if they are to be accessible to our grandchildren and theirs.

These connections are critical not only to our long-term survival as a species, but also in our day to day lives. But because of growing development and human population dynamics, the resources upon which we depend as a species are threatened. The International Union for the Conservation of Nature (IUCN) states "research is very clear about the human need for nature, but this situation is likely to worsen as the global population shifts from 54 per cent of people living in cities today to a forecast 70 per cent by $2050 "$ (IUCN 2014).

Urbanization has many advantages; but one of the disadvantages is the risk of breaking connections between us and our inherited heritage. For example, concrete canyons of buildings, paved streets, and business-focused activity may lead to the loss of understanding of our environmental dependency for clean water, pure air, sustenance and shelter. And if connections between ourselves and our past are shattered, how will we learn to deal with the future? Around the globe there is substantial evidence of these connections being ruptured in contemporary society, in terms of declining biodiversity, in terms of the increasing vulnerability of poor people and in threats to water security. Building knowledge about these 
connections and implementing that knowledge thus becomes an essential endeavor of human development.

Providing careful stewardship of these connections is a goal, but a challenging one in the era of turbulence that characterizes the twenty-first century. Stewardship requires someone, or a group of people, to administer an area, monument or facility, to take care of that heritage, to ensure that the values it curates are indeed accessible to those living in the future as well as the current generation. Marketing destination areas also requires stewardship, although of a different character, one that involves creativity in connecting people with places, in developing interpretive programs that inspire people to learn about their heritage, in creating opportunities for people to have fun and be entertained, and in building opportunities for visitors to have transformative experiences. Solving problems, working with citizens and activists, developing partnerships and engaging in research are direct forms of stewardship as much as patrolling areas, interpreting natural and cultural sites, and maintaining them.

These special places (over 238,00o protected natural areas and many more hundreds of thousands of culturally significant areas as of 2019) are in high demand by the globe's population as places to visit, enjoy for recreation, appreciate and understand. As a result, tens of thousands of destination marketing organizations, development agencies, protected area management and cultural ministries, academics, managers and non-governmental organizations at scales from the local to the global are engaged in ensuring and managing access to them. That job requires an information and knowledge base to better understand what people seek in tourism, what the positive and negative social and biophysical consequences may be, and how tourism may be better managed. Providing opportunities for high-quality experiences is a particularly challenging task given the scale and the often vulnerable character of natural and cultural heritage to visitation that is unmanaged.

When you think about it, this is a pretty hefty responsibility for an industry, that in 2016 accounts, globally, for about 3.1 percent of the direct total global gross domestic product, employs 109 million people directly and about 193 million additional people indirectly. Moving forward, these figures are expected to rise significantly in the next ten years, with more than 381 million people whose jobs depend upon tourism (World Travel and Tourism Council (WTTC) 2017). The WTTC estimates that about three-quarters of all travel spending is for leisure.

The UN World Tourism Organization (UNWTO) expects travel to increase significantly through the year 2030. While 1.235 billion international arrivals were recorded in 2016, the UNWTO predicts 2030 arrivals at 1.8 billion, nearly 50 percent higher than the current level (UNWTO 2011, 2017). These figures reinforce the notion that making sustainability a high priority is the prudent thing to do. The UNWTO defines sustainable tourism as "Tourism that takes full account of its current and future economic, social and environmental impacts, addressing the needs of visitors, the industry, the environment and host communities" (UNWTO 2005). One of the challenges apparent in defining sustainable tourism in this manner is 


\section{Box 1.1}

The small town of Kimmswick, Missouri in the United States provides an example of the challenges and opportunities faced in connecting people with its heritage. Kimmswick is located on the banks of the Mississippi River, just south of the major city of St. Louis, which in the mid-nineteenth century served as the gateway to westward expansion of Euro-American settlement of the U.S.A. Kimmswick itself has a record of human occupation going back approximately 12,000 years, but it was the westward expansion that led to its initial development as the community we recognize today. The town's population, fueled by extraction of iron ore exploded in the late nineteenth century to nearly 1,500 people, and then dropped dramatically to about the 150 or so that populate the community today.

Many of the nineteenth-century buildings have been preserved and contain small businesses catering to tourists, bed and breakfast operations and restaurants. The community is solely dependent on tourism for its economic viability. During the summer months, thousands of tourists, primarily from the local area will crowd the streets, businesses and restaurants enjoying the historical heritage primarily preserved in architecture.

And yet, all is not well. The Mississippi River occasionally floods the grounds of the Busch family (noted for their Budweiser brand of beer) mansion which itself is a destination and an equestrian center. Community leadership on the kind of tourism to attract occasionally falters. The community exists but is subject to changes in the economic situation originating hundreds of miles away, policies developed in the state and national capitals, and forces of climate change occurring at the global level, with little say in any of them. So, while we can say the community still exists, to a large extent as it was 150 years ago, has it been sustained? Is it resilient in the face of global-level trends and forces? Does it hold the vision, leadership and technical skills to survive a century of turbulence?

Kimmswick is broadly representative of thousands of small communities around the globe. They are struggling because of urbanization and abandonment of rural areas, grasping at tourism as the only economic opportunity they see to survive. And so, we ask the question, how can research help these communities develop a viable economic base so they become the vibrant community they want to be? This knowledge covers a wide variety of arenas, not limited to marketing information as generally conceived. But what kind of information would be most useful? Does the community have the capacity to use the information? What kind of capacities does the community need?

that it is often assumed to be a category of tourism, rather than looking at all tourism activity to confront sustainability.

Much of the focus on sustainability is development, making development more sustainable. In fact, 2017 was designated as the UN Year of Sustainable Tourism for Development. The primary goal of this recognition was to advance the UN's 2030 Agenda for Sustainable Development (UN 2015) through the use of tourism. That agenda included 17 goals for development ranging from ending poverty to ensuring access to energy (see Chapter 8 by Anna Spenceley and Andrew Rylance). Tourism will be a significant component of many integrated development strategies that can help make progress toward these goals.

Tourism is often viewed now as a method of development. Tourism activity is widespread around the globe; it has, as noted above, significant economic consequences; it can be an important source of foreign exchange, one that can be 
enhanced relatively easily; and requires less capital investment to create jobs than most other industries. Tourism can, as in other industries, if carefully managed, contribute to local labor income and taxes, encourage the development of local services, particularly health care, provide jobs that allow for upward mobility and otherwise enhance social capital (Shakya 2016). All these can lead to a more fulfilling quality of life for residents in local areas where tourism occurs. And at the same time, tourism carries with it the potential, whether involving visitation to natural or cultural sites, to generate revenues and other benefits that can be used for conservation of these values. Drumm (2007) notes that "Tourism certainly has an enormous potential to be a significant source of conservation finance for financially challenged protected area systems."

And yet, tourism also carries with it the potential for many negative social and environmental consequences, such as along scenically attractive coastlines and within fragile World Heritage Sites like Angkor Archaeological Park in Cambodia, as well as contributing to negative impacts on local cultures that are particularly thorny and difficult to manage. The presence of tourists, particularly large numbers relative to the local population, can disrupt normal societal functions, such as access to areas that provide important ecosystem services, involve culturally or spiritually significant values, or simply make access to locally popular destinations such as beaches or cafes difficult, and make highways and local roads congested (witness the rise of demonstrations against tourism in various European cities that underlie the notion of "overtourism").

Natural and cultural protected areas are not immune to the intense demand for the values they protect. La Tijuca National Park, which protects the mountains in and around Rio de Janeiro in Brazil, but also manages the "Christ the Redeemer" statue (the reason why most of the three million plus visitors go to the park), has had to institute a high-tech visitor use management system. Plitvice Lakes National Park in Croatia is considering something similar. Many other parks have also come to realize that the rapidly growing demand for the values they protect require active management of visitor use as well.

And all of this occurs within a context of turbulence: the twenty-first century is characterized by forces and processes occurring at both global and local levels, sometimes acting synergistically, but very often acting unpredictably and at all times producing volatility, complexity, change and uncertainty (Figure 1.1). Tourism activity and development occurs within this context: change is non-linear-many probable causes may lead to the same or similar effects; temporal delays of varying amounts typify the relationship between an action and its consequence; unanticipated effects ("surprises") often happen; consensus on action often has to be built; and integration of many disciplines is required to solve problems and build a sustainable future.

This book is about building the information and generating the knowledge needed to maintain connections between people and their heritage, both natural and 


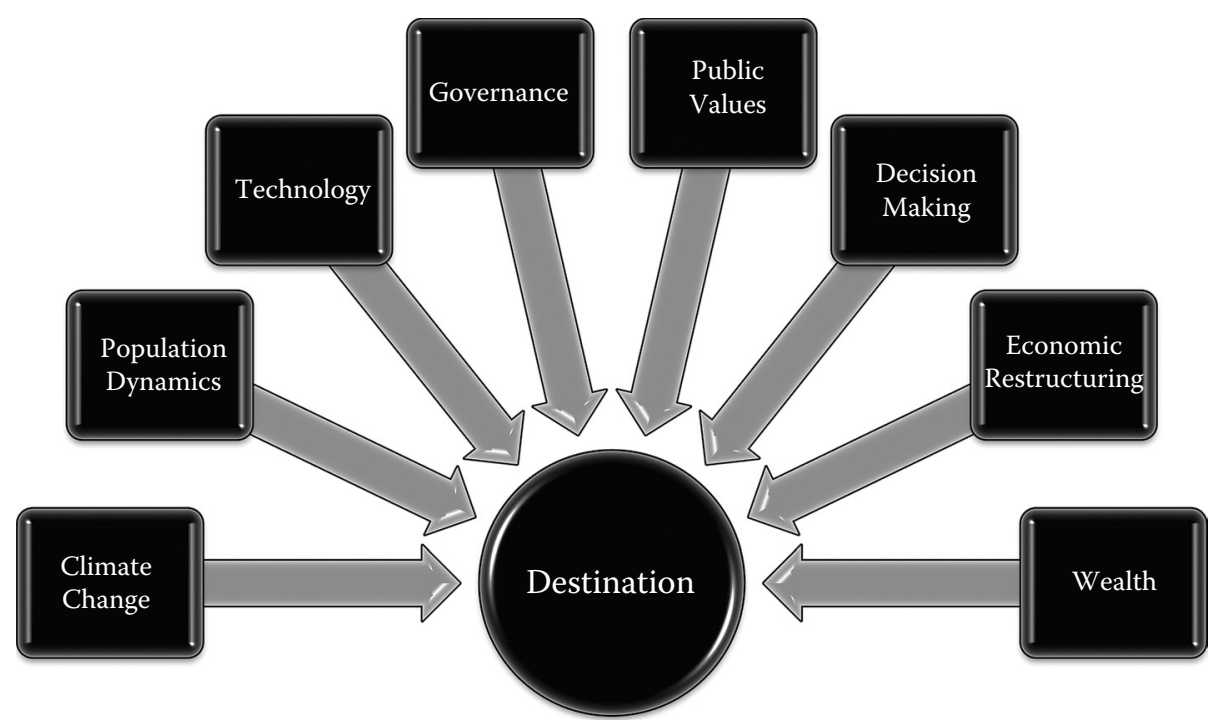

Figure 1.1 Large-scale forces acting upon tourism destinations

cultural. It focuses on connections that are primarily the foundation of tourism, experiences that people have when engaging this heritage, principally in a nonutilitarian way. The chapters identify information and research needs that decision makers can use to inform policy, planning, management and marketing. The book will be helpful primarily to academics and graduate students and other researchers in deciding on thesis and research projects, as well as to managers and granting bodies setting research priorities and making budget decisions. We note that to be useful, research must be relevant to tourism policy and management; we thus have emphasized points in an agenda that are more applied than theoretical, the "low hanging fruit" if you will, research that can be useful in a more immediate sense. Basic research is also a component, but of a more long-term nature.

By itself, research will not solve problems. It can only be applied by policy makers that hold the competency and the will to apply the research and who have the confidence of their constituencies. The research challenges mentioned here would be helpful to such policy makers and managers who recognize their limits and are willing to unite in manager-scientist partnerships that are particularly useful in turbulent contexts.

\section{An era of turbulence}

If there is anything that characterizes the twenty-first century it is that of turbulence. As Kohl and McCool (2016) argue, our context is so volatile, uncertain, complex and ambiguous that the way we plan and manage everything needs to change because, first, the world as we see it has changed, and second, because the basic 
assumptions we have of the world-that it is Predictable, Linear, Understandable, and Stable (referred to as the "PLUS" world) are no longer valid. Because we act as if we live in a PLUS world, we often fail in our planning and management. And many times, it is not just that we fail, but that our actions will sometimes have the opposite effect of what we intended. Now this may be controversial for many readers, but the trends identified earlier occur at different scales and with varying speeds, making uncertainty and nonlinear change a fact of life.

These assumptions led to a paradigm of decision making that was reductionisticsimplifying what were complex systems of components into something that, perhaps a miscasting, we could understand. However, we now realize those assumptions are no longer appropriate or helpful, because they lead us into framing questions, issues and challenges that do not provide useful insights. Kohl and McCool suggest we view the world as Dynamic, Impossible to completely understand, Complex, and Ever-changing (DICE). By changing our assumptions in this way, we see the world through a new lens-a new paradigm - that leads us to new ways of conducting science, decision making and planning.

For example, for decades, tourism marketing organizations assumed that by generating inquiries resulting from magazine advertisements for more information and by sending fulfillment packages to the inquirers, people would in return be convinced to visit the destination. Research showed, however, that conversion rates were relatively low and could not necessarily be predicted by the promotional content. Such promotional-dominated marketing was soon replaced by internet promotion which transformed an assumed linear decision-making process into a complex web of decisions, competing information sources, visitor priorities and preferences, and competitive pricing strategies all with feedback loops. Initially, internet promotion appealed to a relatively small set of tech-savvy users, primarily the young, active and wealthy, interested in exotic places and adventures. However, as the internet grew in importance, promotion of destinations, while still significant, has been expanded to include wholesalers, custom travel itineraries, nonprofit organizations and socially aware providers. This web of interactions, linkages and strategic nodes is itself a complex system. One result is that it has replaced the notion of a value chain with that of a value network, making marketing and delivery of recreation opportunities more complex than ever.

The results of promotion are often unexpected, and not always positive. Often conceived as an efficient and benign strategy for generating foreign exchange, citizens of cities in Europe and other places erupted in 2016 and 2017 in protest against rapidly growing visitation in their cities and neighborhoods. This was colloquially termed "overtourism" because of the congestion and unappreciated behavior of visitors. These protests were unexpected, and to some extent ignored by marketing organizations that heavily promoted tourism. This explosive outbreak of protest shows how marketing organizations, dominated by a promotional mental model of tourism development, forgot that marketing includes product development and quality maintenance. 
Managers of many national parks and protected areas, and some visitors, likewise express concerns over rapidly increasing visitation. Such visitation is claimed to damage natural and cultural heritage and all but ruin visitor experiences. In 2017, for example, a year following the U.S. National Park Service 1ooth anniversary and the launch of its app "Find Your Park" designed to boost visitation, newspapers were peppered with headlines such as "Parks Being Loved to Death," "How Many is Too Many?" and so on. These articles expressed concerns not only about rapidly rising use levels but the consequent impacts of visitation on natural heritage, and on the visitor experience as well. In short, the "fix" of increased promotion has failed to provide the higher quality, transformative experiences that the American National Park Service envisioned in 2012 through its Advisory Board (National Park System Advisory Board 2012).

These "surprises" experienced in both cities and parks have come about because of the growing complexity of the social-ecological systems in which we live, the lack of understanding of those systems, and the absence of a vision of what sustainable tourism is all about. They represent an underlying assumption, often only implicit, that more is better.

This complexity is not a figment of our imagination but characterizes all but the most simple and trivial decisions, leading to wicked problems and messy situations. Wicked problems, briefly described, are those in which society lacks agreement on goals and there is a lack of agreement on cause-effect relationships. Rittel and Webber (1973: 160) argue that:

As distinguished from problems in the natural sciences, which are definable and separable and may have solutions that are findable, the problems of governmental planning-and specially those of social or policy planning-are ill-defined; and they rely upon elusive political judgment for resolution.

Wicked problems have no solution (in the sense of an answer) but are resolved (by agreement or consensus) through political discourse that often uses science as a source of information. Such agreements/resolutions are temporary because the context for them is in a constant state of change. The issue of tourism development and management is the consummate example of a wicked problem, for goals are often left unspecified or frequently articulated in vague or ambiguous terms, focus on inputs (e.g., what actions to take, or, worse, a proposal for an increase in visitation), or at best lack a sense of agreement among the destination populations most affected. There is only an illusion of understanding of causes and effects.

\section{Systems thinking as a response to complexity}

This complexity challenges conventional, reductionistic paradigms of science, including that focused on tourism and recreation. But when "facts are uncertain, 
values in dispute, stakes high and decisions urgent"-certainly a description of many tourism situations-a different kind of science is needed (Funtowicz and Ravetz 1995). Wicked problems occur in situations where scientists disagree on cause-effect relationships and social agreement on goals does not exist. And because of these situations we need to look carefully at the suitability and usefulness of the paradigms currently used to guide research.

How problems are defined in simple, linear systems is evident, but for wicked problems, the definition is "in the eye of the beholder" (Allen and Gould 1986). In wicked systems, problems are defined through public engagement, deliberation, reflection and debate. They are resolved only through similar processes, and therefore the important test of "answers" is their usefulness, rather than their "correctness," which really cannot be determined in messy situations. The way forward in complex situations is to better understand the character of the problem through public engagement and systems thinking. This argument is articulated in this extensive quote from Morris and Martin (2009: 156):

The journey towards sustainability is a 'wicked' problem involving complexity, uncertainty, multiple stakeholders and perspectives, competing values, lack of end points and ambiguous terminology ... In a word, dealing with sustainability means dealing with a mess and most people avoid messes because they feel ill-equipped to cope. The health, agricultural, financial and ecological problems we now face are qualitatively different from the problems for which existing scientific, economic, medical and political tools and educational programmes were designed. Without the right tools, learners faced with these wicked problems may fall back on the same old inappropriate toolbox with at best, disappointing outcomes. Given the messy nature of the dilemmas and contradictions facing us there can be no single recipe and no definitive set of tools. Yet some ways of thinking and of doing things do seem more useful than others in this context. These approaches are as much about 'problem finding' and 'problem exploring' as they are about problem solving. Our contention is that learners cannot deal with the wicked problems of sustainability without learning to think and act systemically.

Sustainable tourism, I believe Morris and Martin would agree, falls within this argument. It is not the simplistic finding of the intersection of ecological viability, economic feasibility and social acceptability. Such an approach implicitly assumes a stable balance among these three partly competing, partly overlapping values. But the world is hardly stable and such assumed balances soon become undone, if they ever were in balance, and thus upset plans long made with this balance implicit. The world is in a constant state of change; some changes are local and fast; others are global and likely slow.

The systems-thinking viewpoint is becoming more popular among tourism scientists (e.g., Farrell and Twining-Ward 2004; Strickland-Munroe, Allison and Moore 2010; Bricker et al. 2015; Hughes, Weaver and Pforr 2015; Kohl and McCool 2016; McCool and Bosak 2016; Espiner, Orchiston and Higham 2017) as a way of dealing with complexity and complex systems. So systems thinking is not just a new 
paradigm; it is a tool to build not only the situational awareness needed in dynamic situations (see e.g., Nkhata and McCool 2012) but it helps build foundations for developing resolutions to problems.

Systems thinking, according to Senge (2006: 68-9),

is a discipline for seeing wholes. It is a framework for seeing interrelationships rather than things, for seeing patterns of change rather than static 'snapshots' ... Today systems thinking is needed more than ever because we are becoming overwhelmed by complexity.

The focus in systems thinking is on the connectedness of actors/actions rather than the characteristics of actors/actions. Systems thinking assumes nonlinear causality and displays connections as a series of feedback loops rather than assuming linear uni-directional connections between causes and effects. Rather than assuming that a one-time event underlies consequences, systems thinking views causality as an ongoing process, with consequences providing feedback to causes. Tourism research has been dominated by conventional thinking, focused on developing knowledge about the parts of a system for the last 50 years. And while this focus has led to an increase in knowledge, we are now at a point where we need to focus on the system rather than its parts to deal with the complexity, change, and uncertainty that characterizes the context for tourism. We need to focus on developing understanding rather than simply knowledge.

Systems thinking starts with defining a distinctive whole and then examining the interconnected parts or components. Systems thinking recognizes that the whole contains emergent properties, that is, characteristics of the whole that cannot be predicted from its parts, just as the thinking property of the human brain cannot be predicted by examining its neurons or the transportation property of an automobile could not be predicted by finding a steering wheel in the desert. A system in this context includes both social and ecological components as both are important components of much of tourism.

In Stage I, we define a system of interest and its boundaries (we note that defining boundaries is not easy, and ultimately there are no exogenous forces or processes). In Stage II, we simplify the system to better understand it and use our knowledge to resolve problems. Stage II represents an effort to build a model of the system-a model being a simplistic representation of the system. This model building and simplification occurs only after we understand the complexity of the situation. Simplifying the system only comes after we have considered the system's distinctive whole and its interconnected parts. The purpose of the modeling is more in the way of understanding how the system works rather than prediction. Stage II helps us understand where delays occur, where leverage points in changing the system outputs arise and how we might organize to engage the complexity of the system. Inevitably, our models will be wrong (Sterman 2002) which means we think and act adaptively to change in response to change. 
Table 1.1 Best practices for functioning in a complex situation

\begin{tabular}{ll} 
Complexity practice & Short description \\
\hline $\begin{array}{l}\text { Build situational awareness } \\
\text { Invest in personal relationships }\end{array}$ & $\begin{array}{l}\text { Heightened awareness to sense the unexpected } \\
\text { Engaging in collaborative forms of governance needed } \\
\text { to manage complex situations } \\
\text { Appreciate the power of networks }\end{array}$ \\
$\begin{array}{l}\text { Networks are needed to characterize simply and } \\
\text { engage complexity } \\
\text { Seek and use leverage points }\end{array}$ & $\begin{array}{l}\text { Leverage points are places in a system to make change } \\
\text { Different forms of knowledge help us understand } \\
\text { complex systems } \\
\text { Uncertainty pervades our world; what once worked } \\
\text { may no longer work }\end{array}$ \\
\hline
\end{tabular}

Note: Following McCool et al. (2015). (For a complete discussion of these practices see that volume.)

In Stage III, we engage this complexity, and do so by implementing in various forms complexity practices identified by $\mathrm{McCool}$ et al. (2015). These practices (Table 1.1) are implemented based on an understanding of the adaptive character of the system, what the system whole may be, and the model we have developed. For example, Anderies, Janssen and Ostrom (2004) have suggested a model of natural resource systems that is scale independent and emphasizes relationships among providers and regulators of interactions in these systems. The process of implementing the practices in Table 1.1 build the social capital needed to address the problems of complex, dynamic systems.

In Figure 1.2, we show a simple depiction of how overtourism can be viewed. Visitation rises and leads to impacts, social and biophysical. A standard of how much change is acceptable exists (however, often only implicit) leading to a gap between what exists and what is acceptable. This leads to management action, often called establishing a carrying capacity implemented through a use limit. The system assumes impacts are linearly related to the number of visitors, and thus, impacts are reduced from implementing the use limit. Unfortunately, this system is simplistically represented, as are the fundamental assumptions at the foundation of carrying capacity (see $\mathrm{McCool}$ and Lime 2001 for a critique). Use limits often lead to surprises, after some kind of delay. Surprises are the unanticipated consequences. For example, implementation of a use limit may shift the burden (Senge 2006) of resolving impact issues to other visitors, other managers (as visitors shift to other areas), or residents of other communities. This systems-thinking approach helps us better understand what happens when we don't perceive the underlying system.

Systems thinking helps us understand not only what is happening in a complex system, but also how the parts are related. This increased understanding helps us not only to propose actions that impact the functioning of the system as a whole, 


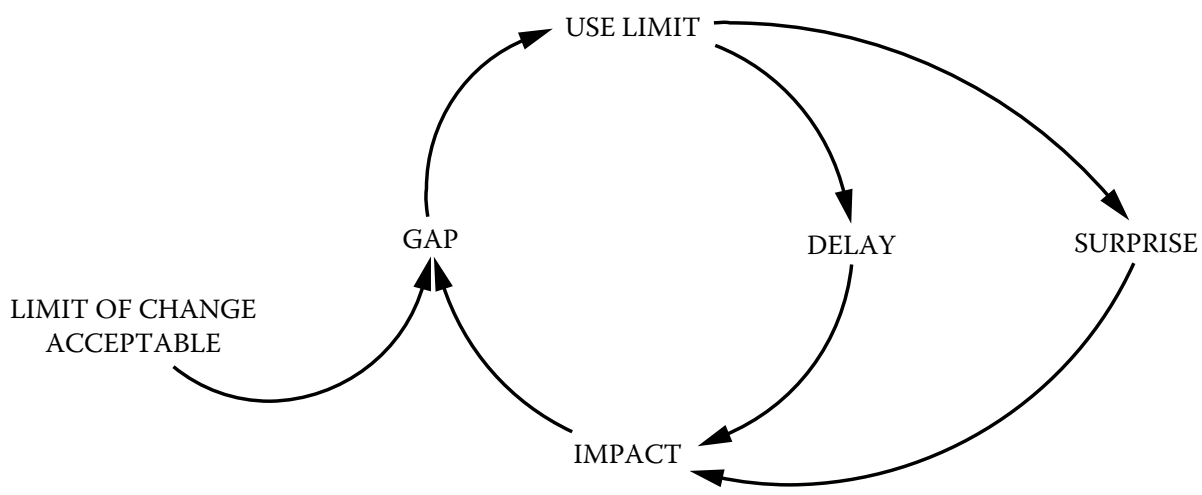

Notes: Here the system "begins" with a level of impact on social systems; this impact is compared, either explicitly or implicitly, to some idea of whether the impact is acceptable, and this leads to selection of a management strategy, here noted as a use limit. This limit leads to, after a delay, a reduction of impact, which in turn will be compared to the standard of acceptability. Sometimes, as shown here, a "surprise" or unanticipated consequence occurs, leading to more or less impact, and the result feeds through the causal loop again.

Figure 1.2 Simple depiction of overtourism using a causal loop diagram

but also may help the system achieve better resilience in the face of the global level processes affecting it. Resilience is the ability of a system to respond to disturbance and retain its structure and function. Resilience is not only a characteristic of the whole system-it can become a goal for management. And by focusing on resilience as a goal, we then also tend to the system as a whole.

For example, we can ask how tourism can be managed instead of or in addition to use limits to make a social-ecological system more resilient, and potentially less vulnerable, to the global-level stresses and strains we all face. We can ask the question, what is it that tourism sustains and should sustain, rather than seeking some mythical conjunction of social acceptability, economic viability and ecological responsibility, all of which represent value judgments on the part of various publics and interests.

\section{Conclusion}

This book is all about identifying the information challenges for sustainable tourism in a century of turbulence as well as opportunity-the turbulence we experience every day as we go to the office or visit the field; the opportunity provided by abandoning the paradigms of the past (unlearning, if you will) that worked well once but now handicap our thinking, and advancing new paradigms which provide a more useful lens through which we see opportunity where others have only seen problems. It is about providing a base for producing policy-relevant research, research that informs management or policy making when it comes to 
choosing among alternatives, understanding the character of a wicked problem, or even framing a messy situation.

Understanding the challenges we have before us through building our awareness helps enhance system resilience. We have included chapters on many, but not all, of the various dimensions or arenas of sustainable tourism, the content of which is influenced by the question of what it is that tourism should sustain. The topics in this book are not necessarily limited to one kind of situation, type of state, geography or constituency. Each one is applicable to all kinds of contexts, but of course are modified to be applicable to any particular social, political or geographical environment. They are designed to stimulate research, and to provide information and knowledge regardless of where one lives, who a person or community may be, or what one does in the context of tourism.

In the following chapters, various authors describe what they believe to be the important research challenges and opportunities by identifying information gaps, needs and significant questions for research, with the result that our understanding of how various tourism-related systems function and how they can be better managed to be resilient in the face of change is enhanced.

Together, they form an agenda for research to make tourism more sustainable, a great need in a world of increasing complexity and scarcity. They suggest that perhaps some of the research questions we as a field have pursued in the past may no longer need to have our attention. They provide opportunities to lay a foundation for addressing the wicked and messy situations of the future. We discuss them now because with substantial tourism growth projections for the near future, we need "to get our act together" to avoid unnecessary turmoil and conflict.

This is particularly important when we view tourism as a developmental action, forcing us to address the questions of what tourism sustains, how we can make tourism development more efficient, effective and equitable, and how we can improve tourism research to make it more relevant and useful in addressing these issues.

\section{References}

Allen, G. M. and Gould Jr, E. M. (1986). "Complexity, wickedness, and public forests." Journal of Forestry, 84(4): 20-23.

Anderies, J. M., Janssen, M. A. and Ostrom, E. (2004). "A framework to analyze the robustness of social-ecological systems from an institutional perspective." Ecology and Society, 9(1): 18. Available at http://www.ecologyandsociety.org/volg/iss1/art18/.

Bricker, K. S., Donohoe, H., Becerra, L. and Nickerson, N. (2015). “Theoretical perspectives on tourisman introduction." In K. S. Bricker and H. Donohoe, eds., Demystifying Theories in Tourism Research, pp. 1-6. Wallingford: CABI.

Drumm, A. (2007). “Tourism-based revenue generation for conservation.” In R. Bushell and P. Eagles, eds., Tourism and Protected Areas: Benefits Beyond Boundaries, pp. 191-209. Wallingford: CABI. 
Espiner, S., Orchiston, C. and Higham, J. (2017). "Resilience and sustainability: a complementary relationship? Towards a practical conceptual model for the sustainability-resilience nexus in tourism." Journal of Sustainable Tourism, 25(10): 1385-1400.

Farrell, B. H. and Twining-Ward, L. (2004). "Reconceptualizing tourism." Annals of Tourism Research, 31(2): 274-95.

Funtowicz, S. O. and Ravetz, J. R. (1995). “Science for the post normal age.” In L. Westra and J. Lemons, eds., Perspectives on Ecological Integrity, pp. 146-61. Dordrecht: Springer.

Hughes, M., Weaver, D. and Pforr, C., eds. (2015). The Practice of Sustainable Tourism: Resolving the Paradox. London: Routledge.

IUCN (International Union for the Conservation of Nature) (2014). "A strategy of innovative approaches and recommendations to improve health and well-being in the next decade." Gland: IUCN.

Kohl, J. and McCool, S. F. (2016). The Future has Other Plans. Denver, CO: Fulcrum.

McCool, S. F. and Bosak, K., eds. (2016). Reframing Sustainable Tourism. Dordrecht: Springer.

McCool, S. F., Freimund, W. A., Breen, C., Gorricho, J., Kohl, J. and Biggs, H. (2015). "Benefiting from complexity thinking." In G. L. Worboys et al., eds., Protected Area Governance and Management, pp. 291-326. Canberra: ANU Press.

McCool, S. F. and Lime, D. W. (2001). "Tourism carrying capacity: tempting fantasy or useful reality?" Journal of Sustainable Tourism, 9(5): 372-88.

Morris, D. and Martin, S. (2009). "Complexity, systems thinking and practice.” In Arran Stibbe, ed., The Handbook of Sustainability Literacy, pp. 156-64. Totnes: Green Books.

National Park System Advisory Board (2012). "Revisiting Leopold: resource stewardship in the national parks." Washington, D.C.: National Park System Advisory Board, National Park Service.

Nkhata, B. A. and McCool, S. F. (2012). "Coupling protected area governance and management through planning." Journal of Environmental Policy E Planning, 14(4): 394-410.

Rittel, H. W. and Webber, M. M. (1973). "Dilemmas in a general theory of planning." Policy Sciences, 4(2): 155-69.

Senge, P. M. (2006). The Fifth Discipline: The Art and Practice of the Learning Organization. London: Random House.

Shakya, M. (2016). "Tourism and social capital: case studies from Nepal.” In S. F. McCool and K. Bosak, eds., Reframing Sustainable Tourism, pp. 217-39. New York: Springer.

Sterman, J. D. (2002). "All models are wrong: reflections on becoming a systems scientist." System Dynamics Review, 18(4): 501-31.

Strickland-Munro, J. K., Allison, H. E. and Moore, S. A. (2010). "Using resilience concepts to investigate the impacts of protected area tourism on communities." Annals of Tourism Research, 37(2): 499-519.

United Nations (2015). "Transforming our world: the 2030 agenda for sustainable development." New York: United Nations.

UNWTO (UN World Tourism Organization) (2005). "Making tourism more sustainable: a guide for policy makers." Madrid: United Nations.

UNWTO (UN World Tourism Organization) (2011). “Tourism towards 2030/global overview.” Madrid: United Nations.

UNWTO (UN World Tourism Organization) (2017). “2016 Annual Report.” Madrid: United Nations.

World Travel and Tourism Council (2017). “Travel and tourism economic impact 2017." London: World Travel and Tourism Council. 